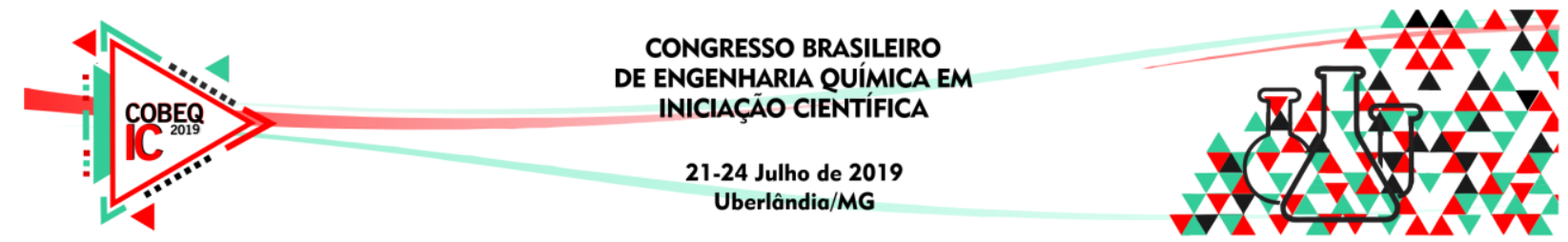

\title{
DESENVOLVIMENTO DE PROTÓTIPOS EXPERIMENTAIS DE PROCESSOS QUÍMICOS PARA APRESENTAÇÃO EM FEIRAS DE TECNOLOGIA EM ESCOLAS PÚBLICAS DA REGIÃO DE CAMPINAS/SP
}

\author{
R. B. SILVA, L. S. VIGNATTI, V. A. BENETI, L. B. ROSALES, F. V. SILVA
}

Universidade Estadual de Campinas (UNICAMP), Faculdade de Engenharia Química Departamento de Engenharia de Sistemas Químicos

E-mail para contato: flaviovs@unicamp.br

\begin{abstract}
RESUMO - As Feiras de Ciências estudantis são muito tradicionais nas escolas públicas e privadas no Brasil possuindo um histórico de mais de cinco décadas, tornando-se uma excepcional oportunidade para estudantes apresentarem suas produções científicas escolares. Entretanto, observa-se nestes eventos uma predominância das ciências básicas, abrindo-se uma considerável lacuna na divulgação e, principalmente na disponibilidade de conhecimentos de tecnologias presente no cotidiano. Assim, este trabalho consiste no desenvolvimento e montagem de protótipos experimentais relacionados a processos da Engenharia Química que serão apresentados em Feiras de Tecnologia organizadas em Escolas Públicas na região metropolitana de Campinas. A Feira de Tecnologia é uma ação pedagógica com objetivo de estimular e promover a formação dos estudantes da rede pública de ensino, no âmbito da Engenharia Química, inserindo-os no contexto da pré-Iniciação Científica. Diferente da tradicional Feira de Ciência, o foco principal da Feira de Tecnologia é apresentar, de forma acessível e fácil, conceitos tecnológicos de processos corriqueiros, proporcionando aos estudantes do ensino médio a oportunidade de se familiarizarem com diferentes aspectos tecnológicos de forma visual e palpável e, por consequência, mais impactante. Os alunos do programa de Educação Tutorial (PETEQ) participam ativamente das atividades deste projeto e serão responsáveis pela organização da Feira de Tecnologia nas Escolas Públicas.
\end{abstract}

\section{INTRODUÇÃO}

De acordo com o conceito apresentado pelo Ministério da Ciência, Tecnologia, Inovações e Comunicações (MCTIC), “...feiras de ciências caracterizam-se como espaços pedagógicos, revolucionários, destinados à apresentação de projetos de pesquisa, com fundamento científico, em diversas áreas do conhecimento humano, realizados por jovens cientistas do ensino médio e da educação profissional técnica de nível médio. Assim, as Feiras de Ciências e Mostras Científicas são ferramentas ideais para transformar a teoria em prática, já que são espaços que, em um primeiro momento, estimulam a aplicação de conhecimentos no desenvolvimento de projetos ligados a diversas disciplinas para, posteriormente, servirem de palco destinados à exposição desses projetos, em especial 


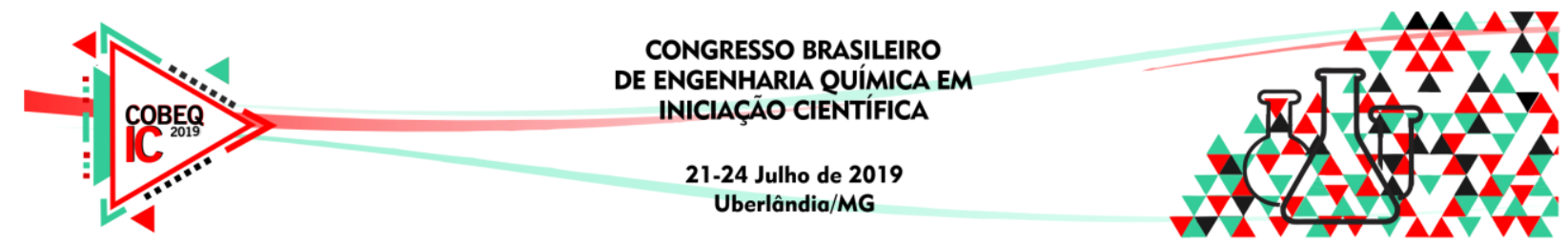

experimentos, pesquisas ou outras formas de trabalho investigativo, informativo, inovador ou tecnológico, realizados por alunos com a mediação de seus professores...” (MCTI, 2019).

Assim, destaca-se o papel incentivador de vocações e visões críticas dos indivíduos envolvidos na atividade (tanto para os expositores quanto os visitantes) e, ainda, impulsionar o desenvolvimento de projetos direcionados à resolução de problemas sociais, e ambientais, aptos a apontar a solução de problemas específicos do cotidiano ou até mesmo de problemáticas ligadas a questões econômicas, sociais e ambientais, reforçando o sentimento de pertencimento em seus participantes e contribuindo significativamente para o progresso científico e tecnológico do país.

Entretanto, comumente não é observado um direcionamento das Mostras Científicas para uma divulgação de tecnologias. No sentido de contribuir para a modificação deste cenário este projeto foi direcionado para o desenvolvimento e montagem de protótipos experimentais relacionados a processos da Engenharia Química que serão utilizados em Feiras de Tecnologia organizadas em Escolas Públicas de Campinas.

O projeto está inserido no Programa de Iniciação Científica para o Ensino Médio (PIBIC-EM), onde três alunos de escolas públicas da região de Campinas são selecionados para participarem do desenvolvimento de um projeto de iniciação científica na Unicamp. Participam também deste projeto alunos do Grupo PET Engenharia Química que acompanham todas as atividades realizadas pelos alunos do ensino médio.

Durante a primeira fase do projeto do PIBIC-EM foram realizados estudos e discussões sobre engenharia química e suas principais tecnologias com o intuito de definir a processo químico base da Feira de Tecnologia que será organizada nas escolas públicas de Campinas. Entre os temas propostos e debatidos foi escolhido a produção do ácido sulfúrico, sobre a qual foram realizadas diversas pesquisas. Este processo será apresentado de uma forma mais prática, utilizando protótipos de equipamentos utilizados na produção do ácido sulfúrico, junto com ilustrações do processo para o melhor entendimento do público e destacando a importância do ácido sulfúrico no meio industrial. Com base na revisão teórica, foram elaborados um texto explicativo sobre o Ácido Sulfúrico, um diagrama de blocos e um primeiro protótipo de trocador de calor casco-tubo está em fase final de desenvolvimento.

\section{PROCESSO BASE DA FEIRA DE TECNOLOGIA - PRODUÇÃO DE ÁCIDO SULFÚRICO.}

O ácido sulfúrico é muito importante, pois se trata de um ácido extremamente potente e essencial para a indústria química. Ele é utilizado na fabricação de fertilizantes, na indústria petroquímica, fabricação de papel, bateria de automóveis, ácidos, sais minerais e inseticidas, tratamento da água, produção de explosivos e decapagem de metais. Devido à sua importância e às suas aplicações, o ácido sulfúrico desperta muito interesse em alunos do ensino médio, de forma que se torna bastante interessante a apresentação de seu processo de produção nas escolas, para estimular e instigar esses estudantes por meio da Feira de Tecnologia a conhecerem a vida acadêmica e a Engenharia Química. Para isso, foi construída uma maquete 


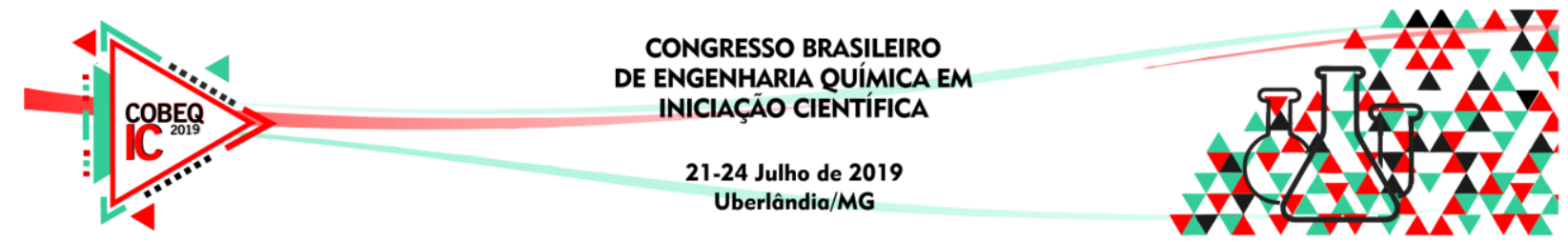

que irá possibilitar uma visualização espacial de como seria uma planta do processo de produção do Ácido Sulfúrico, para usar como uma forma de apresentação ilustrativa na Feira de Tecnologia, facilitando o entendimento do público.

Inicialmente, os temas propostos para discussão foram a produção do ácido sulfúrico e a produção de etanol. Após uma série de debates, o tema escolhido foi o ácido sulfúrico, pela sua grande versatilidade no mercado industrial, sua grande demanda de produção, sua grande importância para os países, chegando a demonstrar o quanto um país é desenvolvido na parte industrial pelo seu uso, e também porque é algo de grande interesse para os jovens.

\subsection{Construção da Maquete do Processo de Produção do Ácido Sulfúrico}

Baseado no estudo preliminar sobre as etapas e equipamentos utilizados nas plantas de produção de ácido sulfúrico, foi construída uma maquete representativa do processo, que é apresentada na Figura 1. Ela possui estruturas feitas a partir de materiais recicláveis, de forma a diminuir o custo do projeto e os impactos ambientais do mesmo.

Foram utilizados materiais tais como: latinhas de alumínio, garrafas pet, tampinhas de garrafas pet, rolo de papel alumínio, caixas de fósforo, papelão, caixa de leite e jornal para o revestimento das estruturas com o papel machê, isopor, entre outros.

Figura 1 - Maquete do processo de produção do ácido sulfúrico (em fase de finalização).

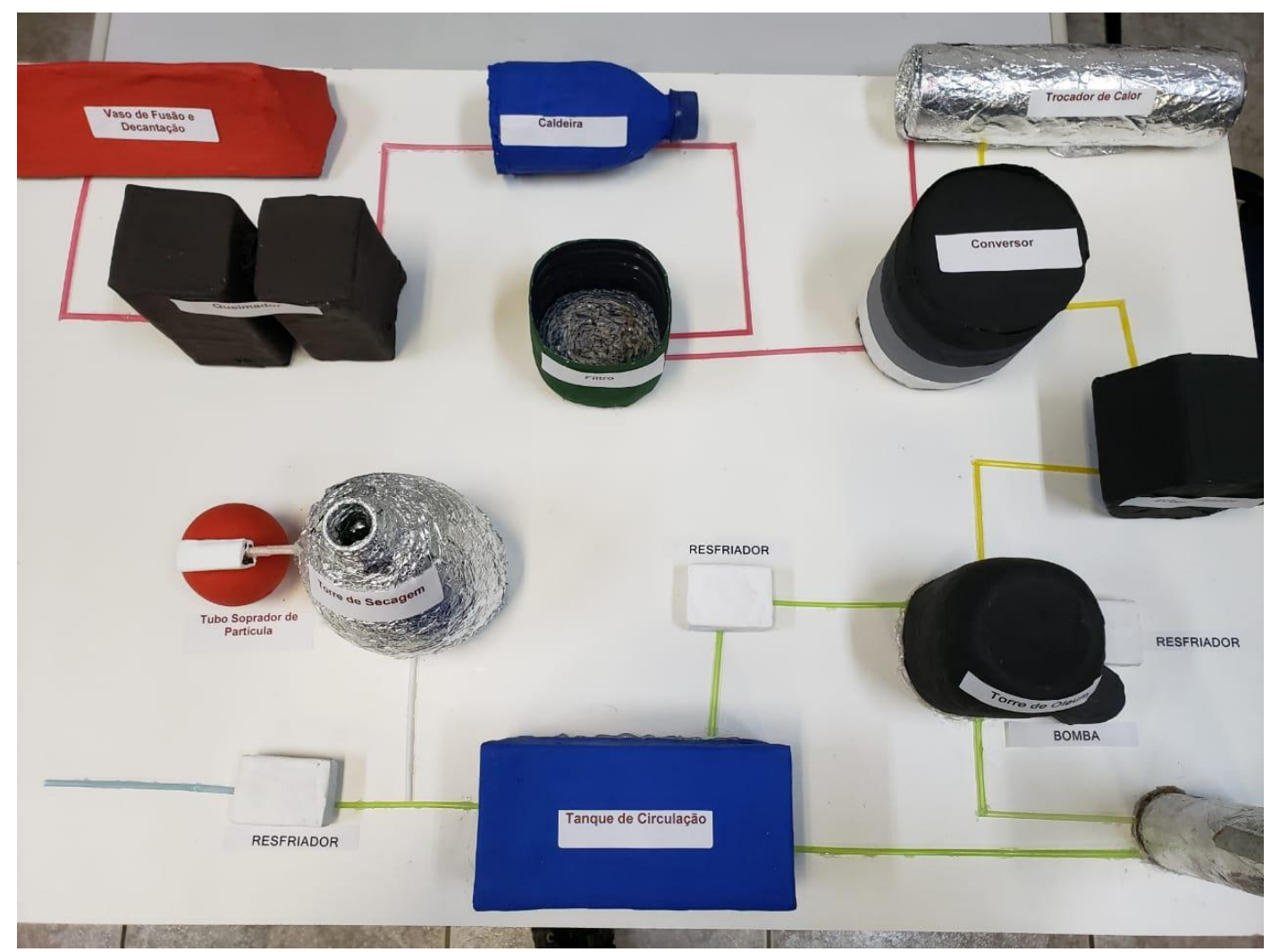



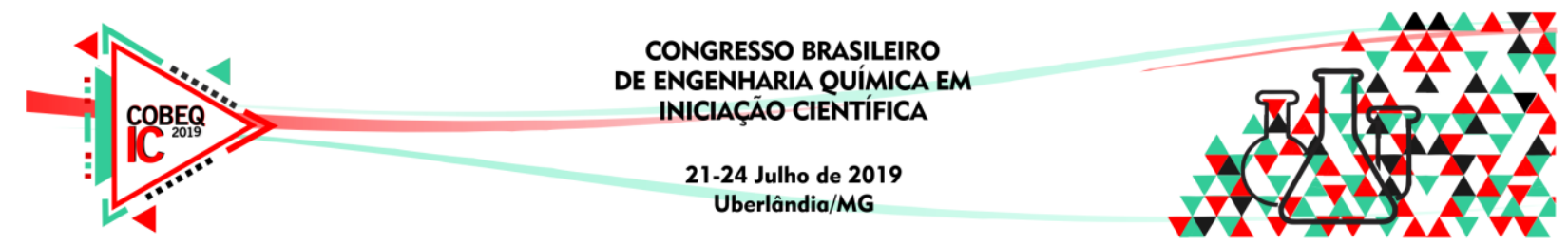

\subsection{Diagrama de Blocos do Processo de Produção do Ácido Sulfúrico}

Um diagrama de blocos foi construído para a demonstração do processo aos participantes da Feira de Tecnologia, de uma maneira sintetizada, facilitando a explicação e a visualização das etapas do processo, tornando mais dinâmicas a apresentação e a aprendizagem dos alunos.

O diagrama de blocos foi feito com base em outro diagrama encontrado na literatura, o que facilitou a aprendizagem sobre como construir um diagrama de blocos. O diagrama construído é apresentado na Figura 2, juntamente com uma legenda que indica quais substâncias estão presentes em cada uma das correntes.

Figura 2 - Diagrama de blocos do processo de ácido sulfúrico

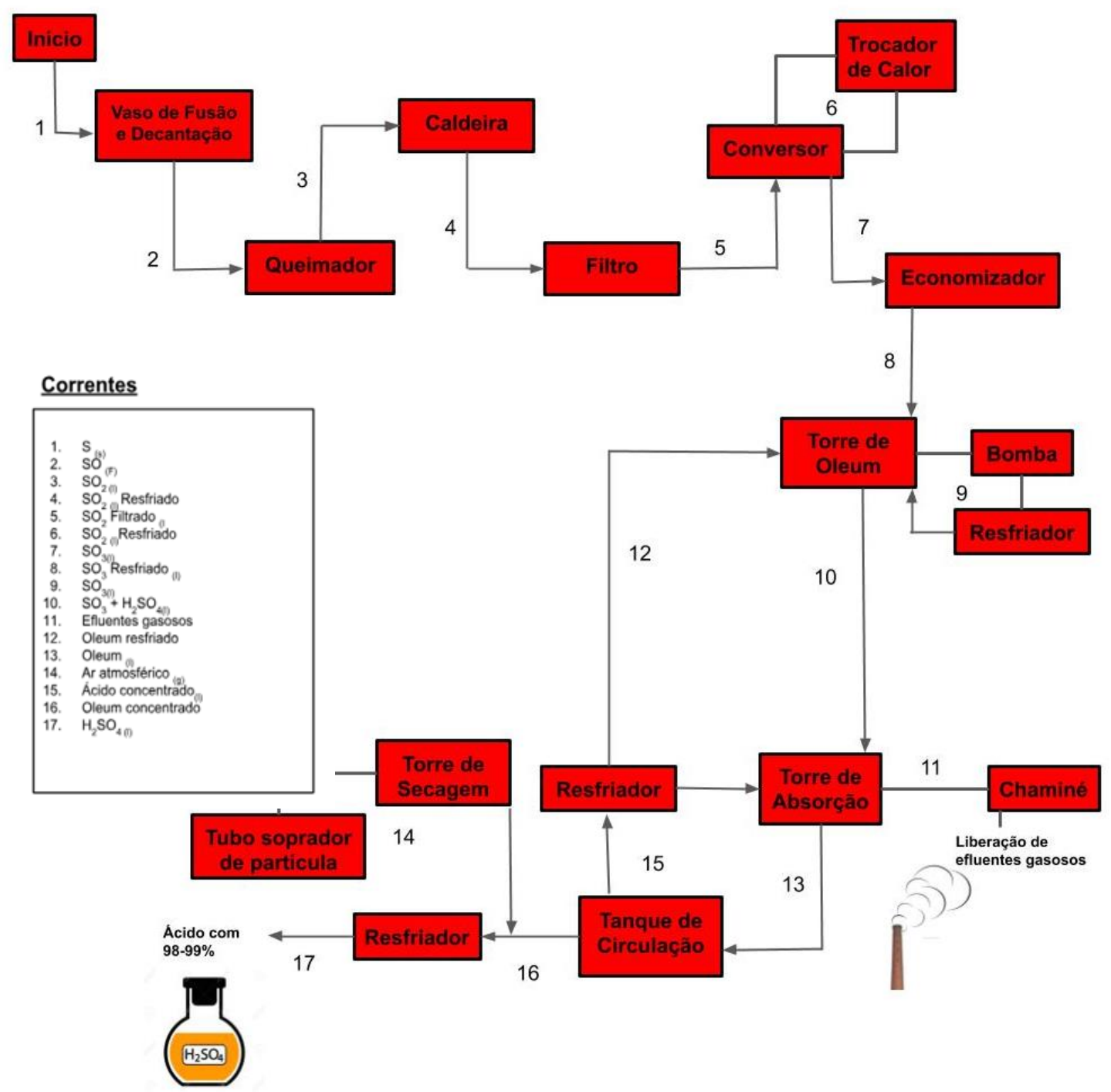




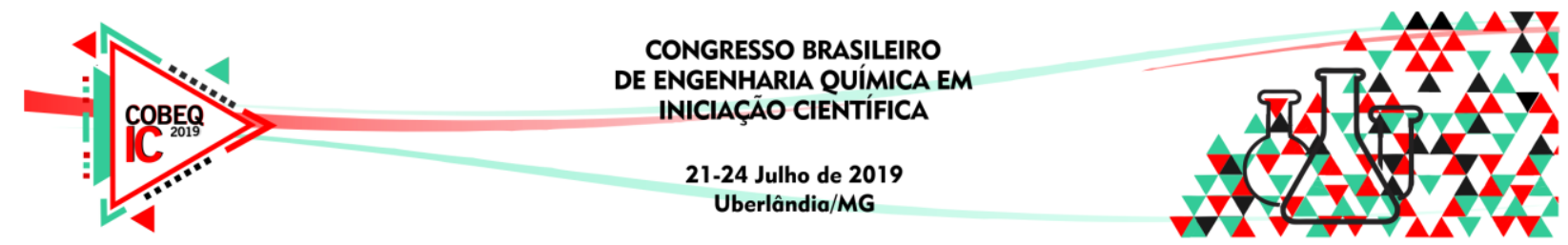

\subsection{Construção do Primeiro Protótipo: Trocador de Calor Casco Tubos}

O primeiro protótipo escolhido para projeto e construção foi um trocador de calor (casco e tubos), o qual é presente no processo de produção do ácido sulfúrico tendo a finalidade de resfriar os gases reagentes antes de serem conduzidos ao primeiro estágio do conversor (corrente 6 da Figura 2 - Diagrama de blocos do processo de ácido sulfúrico). Esse trocador específico é constituído por um casco cujo interior possui um feixe de tubos.

No trocador de calor há circulação de dois fluidos em contracorrente: um passando pelo interior dos tubos e outro pelo casco. No protótipo em desenvolvimento o fluido do interior dos tubos será aquecido, enquanto o fluido do casco será resfriado. O protótipo é constituído por um casco de acrílico, tubo internos de vidro, reservatório de acrílico, duas bombas para circulação dos fluidos, e uma resistência elétrica para o aquecimento do fluido quente.

Figura 3 - Protótipo do Trocador de Calor (em desenvolvimento)

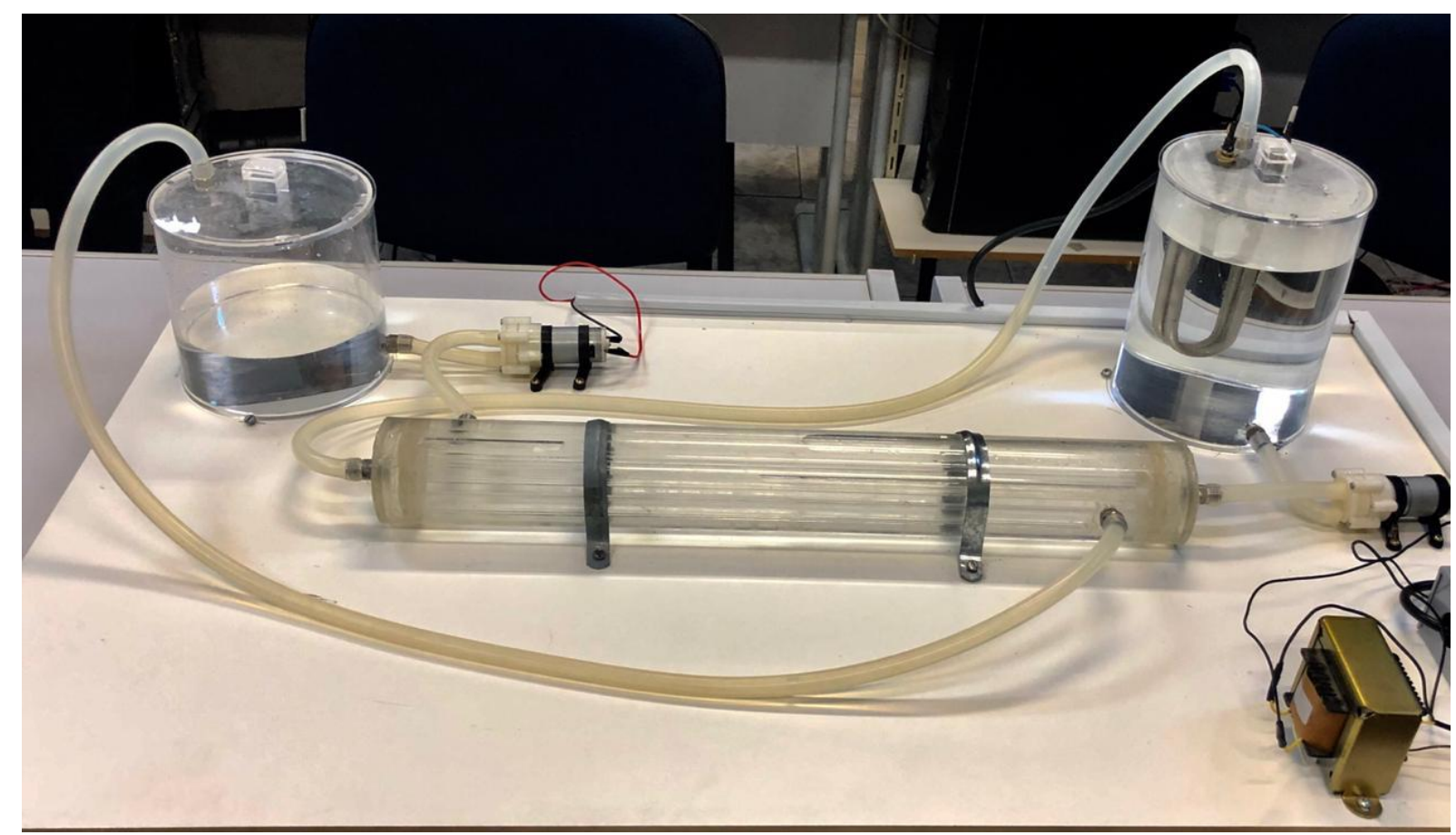

\section{CONCLUSÕES PARCIAIS}

Considera-se como aspectos relevantes nesta primeira fase do projeto o entendimento e o conhecimento aprofundado do processo de produção do ácido sulfúrico; a convivência dos alunos do ensino médio com o dia-a-dia acadêmico; a concepção e montagem dos protótipos, o entendimento conceitual da Engenharia Química, entre outros ganhos.

Durante o desenvolvimento do projeto, vivenciou-se diversas falhas e acertos nos processos, gerando desafios e desenvolvimento próprio por buscar soluções. Pesquisou-se e 


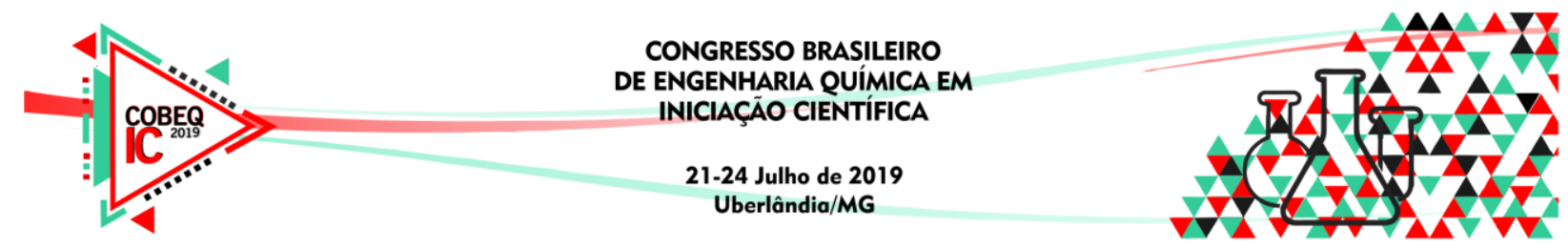

aprofundou-se em processos industriais e seus meios físicos envolvidos, reações, cálculos e conceitos em geral que engloba a Engenharia Química.

Um dos meios que serão utilizados intensamente nas escolas onde ocorrerão as Feiras de Tecnologia são os recursos de demonstrações visuais e práticas através dos protótipos, além da maquete e do slide. Essas ferramentas facilitarão o entendimento dos alunos, deixando as apresentações mais didáticas e interessantes, junto a isso, transmitindo uma boa explicação da importância do ácido sulfúrico para a indústria mundial, suas principais utilidades, trazendo algo distante do cotidiano, que é muito importante para a aprendizagem. Abordando em paralelo a importância da Engenharia Química nas nossas vidas.

Observa-se, claramente que esta experiência está sendo muito proveitosa para os alunos do ensino médio e que o envolvimento com conteúdo das áreas de exatas e tecnológicas promovem uma perspectiva diferenciada sobre a Engenharia como um todo, aumentando o interesse futuro nesta importante área.

\section{AGRADECIMENTOS}

Os autores gostariam de deixar registrado o profundo agradecimento a Joyce Gomes Gabriel, Lívia Chagas Gomes Petrin, Luiz Henrique Silva Albino, Maryenne Sayuri Missawa Moma e Rodrigo Presence Bagarolo (Membros do Grupo PET Engenharia Química) que participaram ativamente no desenvolvimento deste trabalho.

\section{REFERÊNCIAS}

CAMPOS, Vinícius Rangel. Métodos de Preparação Industrial de Solventes e Reagentes Químicos. Revista Virtual de Química, Niterói, v. 3, n. 3, p.210-214, 20 jun. 2011.

TONIN, Paulo César; NEGRÃO, Cezar Otaviano Ribeiro. MONITORAMENTO DA PERFORMANCE TÉRMICA DE TROCADORES E REDES DE TROCADORES DE CALOR. 2003. 6 f. Tese (Doutorado) - Curso de Engenharia Mecânica, Centro Federal de Educação Tecnológica do Paraná, Curitiba, 2003.

MORGADO, Ana; CARDOSO, Francisco; ALVES, Inês. O Enxofre e o Ácido Sulfúrico. 2012. 38 f. Dissertação (Mestrado) - Curso de Engenharia Química, Faculdade de Engenharia Universidade do Porto, Porto, 20.

Queimadores.

Disponível em:<https://web.ist.utl.pt/luis.roriz/MyPage/et_T34.htm>Acesso em: 27 de Novembro de 2018

CARVALHO, Nilza. Fabricação de Ácido Sulfúrico pelo processo de contato. Disponível em: $<$ http://engenharianossadecadadia.blogspot.com/2014/05/fabricacao-de-acidosulfurico-pelo.html>Acesso em: 23 de Agosto de 2018 